Int. J. Dev. Biol. 66: 243-252 (2022)

https://doi.org/10.1387/ijdb.220008nz

\title{
Hyaluronan receptor CD44: developmentally regulated expression and role in the early chick embryo
}

\author{
KONSTANTINOS KONSTANTOPOULOS, ALEXANDROS DIMIROPOULOS, NIKOLAS ZAGRIS* \\ Division of Genetics and Cell and Developmental Biology, Department of Biology, University of Patras, Patras, Greece
}

\begin{abstract}
CD44 is a membrane glycoprotein and is the main receptor for hyaluronan. We studied CD44 expression and spatio-temporal distribution by RT-PCR and immunofluorescence, and used an anti-CD44 blocking antibody to perturb CD44-depended signalling programs in the early chick embryo. The intense CD44 levels we detected in the morula embryo (XI) were of particular interest, suggestive of a maternally stored transcript. Intriguingly, the early presence of CD44 seemed to be essential for the rapid synthesis of hyaluronan. At stage XIII (blastula), CD44 expression was intense in the epiblast and hypoblast. During gastrulation (HH3-4), the cells ingressing into the primitive groove and migrating, and the blood islands, expressed CD44 intensely. At HH8, the folding neural plate showed polarity regulation of CD44 expression, and expression was also intense in neural crest, notochord, and blood islands. During early organogenesis, CD44 was expressed intensely in the developing cranial and caudal neural tube that showed polarity regulation, in optic stalks, otic vesicles, pre-and migratory neural crest cells, ganglia, notochord, pharynx, gut, liver, aortae, heart, somites, vascular area, amnion and chorion, and was distinct in extracellular matrix of cranial neural tube and otic vesicle lumens. Antibody-mediated perturbation of CD44 function resulted in unorganized extracellular matrix, loss of tissue spaces, grossly abnormal notochord, intermingling of clumped neuroectoderm and mesenchyme, absence of somites and blood vessels and inhibition of neural crest cell emigration. CD44 has various pivotal roles in matrix integrity and tissue patterning, consistent with its known biochemical features and interactions with hyaluronan, growth factors, receptors and other signaling molecules.
\end{abstract}

KEYWORDS: CD44, maternal-to-zygotic transition, cell adhesion molecule, hyaluronan, chick embryogenesis

\section{Introduction}

CD44 is a cell surface glycoprotein that can also occur in a proteoglycan form, and as an integral constituent of the extracellular compartment. The mature CD44 protein has a short cytoplasmic tail, a transmembrane domain, and an ectodomain that contains the glycosaminoglycan attachment site(s), and in association with partner proteins, monitors changes in the extracellular matrix and organizes cellular signaling cascades.

Originally identified on the surface of SV-40 transformed 3T3 fibroblasts (Hughes and August, 1981), CD44 was subsequently shown to be expressed in diverse cell types from hematopoietic cells, lymphocytes, macrophages, proliferating epithelial cells to neural glial cells, and in adult tissues including the brain, lung, smooth muscle (Trowbridge et al., 1982; Alho and Underhill 1989; Flanagan et al., 1989; Picker et al., 1989). In the developing embryo, CD44 was expressed at high levels in the heart, somites and con- densing limb-bud mesenchyme in mice (Wheatley et al., 1993) and nearly all organs in rats (Weber et al., 1996) during organogenesis.

CD44 is a family of related proteins that exists in multiple functionally distinct isoforms generated by alternative splicing of

\begin{abstract}
Abbreviations used in this paper: a, dorsal aorta; am, amnion; ar, first aortic arch; av, ventral aorta; b, blastoderm; bc, blastocoele; bl, blood islands; c, neural crest cells; ce, endocardium; ch, chorion; cj, cardiac jelly; cm, myocardium; cv, anterior cardinal vein; $\mathrm{d}$, diencephalon; dc, dorsal mesocardium; dm, dermomyotome; $\mathrm{dv}$ ductus venosus; e, epiblast; ec, ectoderm; em, extracellular matrix; en, endoderm; g, gut; gl, ganglia VII\&VIII; h, hypoblast; $\mathrm{HH}$, stage according to Hamburger and Hamilton; i, infundibulum; I, hepatic primordium(liver); m, migratingmesenchymal cells; me, mesoderm; mn, mesonephros; mp, myelencephalon; ms, mesencephalon; mt, metencephalon; n, notochord; nf, neural folds; ng, neural groove; nt, neural tube; op, optic stalk; ot, otic or auditory vesicle; p, pharynx; ps, primitive streak; r, Rathke's pouch; s, somite; sc, sclerotome; sl, splanchnic mesoderm or splanchnopleure; st, somatic mesoderm or somatopleure; $v$, vitellinemembrane; ve, ventricle; $X$, stage according to Eyal-Giladi and Kochav.
\end{abstract} *Address correspondence to: Nikolas Zagris. Division of Genetics and Cell and Developmental Biology, Department of Biology, University of Patras, Patras, Greece.
E-mail: zagris@upatras.gr | https://orcid.org/0000-0001-7125-3185 
the pre-mRNA; alternative splicing occurs at the proximal plasma membrane external region due to exon insertions (v1-v10), resulting in the enlargement of the CD44 ectodomain. The smallest CD44 isoform does not include any variant exons, is termed standard CD44 (CD44s) and is the most common and widely expressed (reviewed by Günthert, 1993; Sherman et al., 1994). The expression of CD44v isoforms that contain a variable number of exon insertions ( $v 1-v 10)$ is much more restricted, exhibits highly specialized patterns of expression and seems to have a pivotal role in cellular interactions during pattern formation and haematopoiesis. In the developing embryo, CD44 isoforms were expressed in mouse and rat limb bud apical ectodermal ridge (Wheatley et al., 1993; Sherman et al., 1998), mouse neurons in the developing optic chiasm (Sretavan et al., 1994), and in distinct epithelial layers and cells of the rat haematopoietic system (Weber et al., 1996).

CD44 is the major receptor and a cell-binding site for hygroscopic glycosaminoglycan hyaluronan, a virtually ubiquitous component of the extracellular matrix, and coordinates the functions of hyaluronan during development, tissue homeostasis and decease (Aruffo et al., 1990; reviewed by Underhill 1992; Knudson 1998). The CD44 ectodomain may carry chondroitin sulfate and/or heparan sulfate side chains, enabling CD44 to bind to several diverse molecules including fibronectin, collagens, osteopontin, matrix metalloproteinases (MMPs) and growth factors. The selective expression of CD44 protein variants, combined with controlled variations in glycosaminoglycan composition, leads to extensive CD44 structural and functional diversity. Multivallent interactions of CD44 with hyaluronan promote the activation of multiple signalling receptors (ErbB2, EGFR, VEGFR, PDGFR $\beta$, c-MET, TGF $\beta R 1$ ), induce changes in the actin cytoskeleton through binding to ERM (ezrin, radixin and moesin) proteins, and mediate normal and abnormal physiological events including assembly of pericellular matrices, cell migration and proliferation, adhesion, differentiation, matrix remodelling, tissue morphogenesis, lymphocyte lymph node homing, $\mathrm{T}$ cell activation, cancer and metastasis, hyaluronan endocytosis and its subsequent degradation (Culty et al., 1992; Underhill, 1992; Hua et al., 1993; Knudson and Knudson, 1993; Lesley et al., 1993; Sherman et al., 1994; Knudson 1998; Knudson et al., 2002; Rousche and Knudson, 2002; Cichy and Pure, 2003; Ponta et al., 2003; Thorne et al., 2004; Toole, 2004; Evanko et al., 2007; Skandalis et al., 2014; Tavianatou et al., 2019).

Although a great amount of information is available on the structural and biochemical features and the interaction of CD44 with hyaluronan and other molecules during tumour progression and in adult tissues, there are few studies on CD44 expression and function in the early embryo. Previous interesting studies showed expression and illuminated certain features of CD44 in the developing mouse and rat embryos (Wheatley et al., 1993; Weber et al., 1996). Surprisingly, very little is known about CD44 expression in the chick embryo (Corbel et al., 2000). In our work here, we showed that CD44 was expressed as early as stage XI (homologous to the morula in amphibians) and such early CD44 presence was suggestive of a maternally stored transcript. Moreover, we presented a detailed spatio-temporal developmental profile of the CD44 expression pattern in the very early chick embryo from stage $\mathrm{XI}$ to the early organogenesis (stage $\mathrm{HH} 17,29$ somites). To investigate the developmental significance of the CD44 expression pattern in the early embryo, we used blocking antibodies directed against CD44 to perturb CD44-depended signalling programs.

\section{Results}

\section{Expression of the CD44 gene in the early embryo}

In our present work, RT-PCR was performed to determine the developmental expression of the CD44 gene in the early chick embryo. Total RNA was isolated from embryos at stages XII (early blastula), $\mathrm{HH} 2$ (initial streak/early gastrula), $\mathrm{HH} 4$ (definitive streak/ gastrula), $\mathrm{HH} 5$ (head-process) and late stage $\mathrm{HH} 13$ (HH13+, 20to-21 somites). The results showed bands of the predicted size of 226 bp for CD44 and 187 bp for $\beta$-actin (Fig. 1); no products were

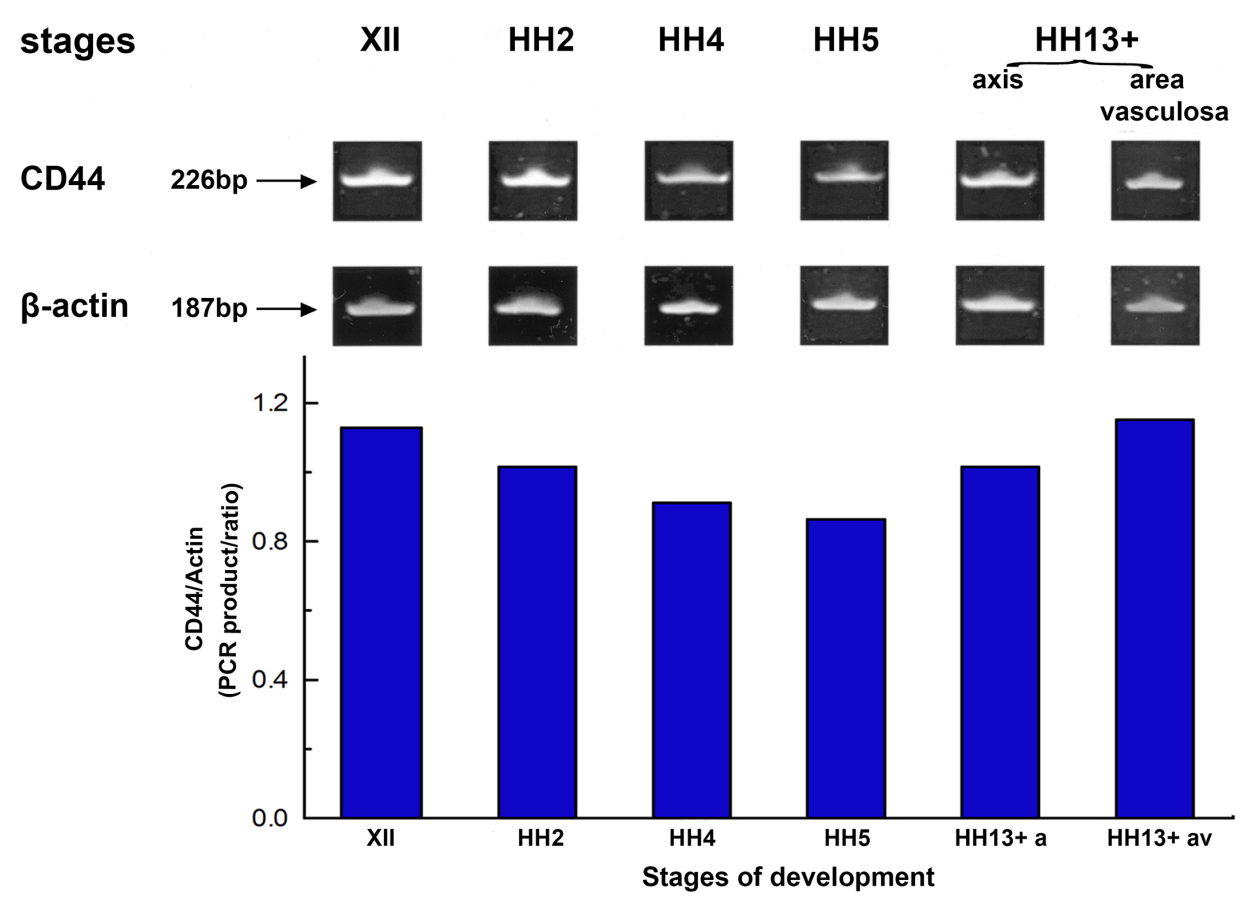

Fig. 1. The expression pattern of the CD44 gene in early chick embryo determined by RT-PCR. Representative gel stained with ethidiumbromide of RT-PCR amplification products of the 226-bp CD44 and the 187-bp $\beta$-actin cDNA produced by specific primers. Total RNA isolated from stages XII (early blastula), HH2 (initial streak/early gastrula), $\mathrm{HH} 4$ (definitivestreak), $\mathrm{HH}$ (head process) and late stage $\mathrm{HH} 13$ ( $\mathrm{HH} 13+, 20-21$ somites) of chickembryos was used as template. Embryos at late stage $\mathrm{HH} 13$ were micro-dissected and RNA was isolated from the embryonic axis (axis) and the area vasculosa, separately. PCR amplification of $\beta$-actin serves as a load control. CD44 showed high transcript levels in stage XII embryos, a progressive slight decrease up to stage $\mathrm{HH} 5$, and then showed an increase in late stage HH13 embryos. Quantification of CD44 mRNA levels determined by scanning densitometry and computer integration of the gel are expressed as a function of $\beta$-actin levels shown schematically by the histogram below the gel. 

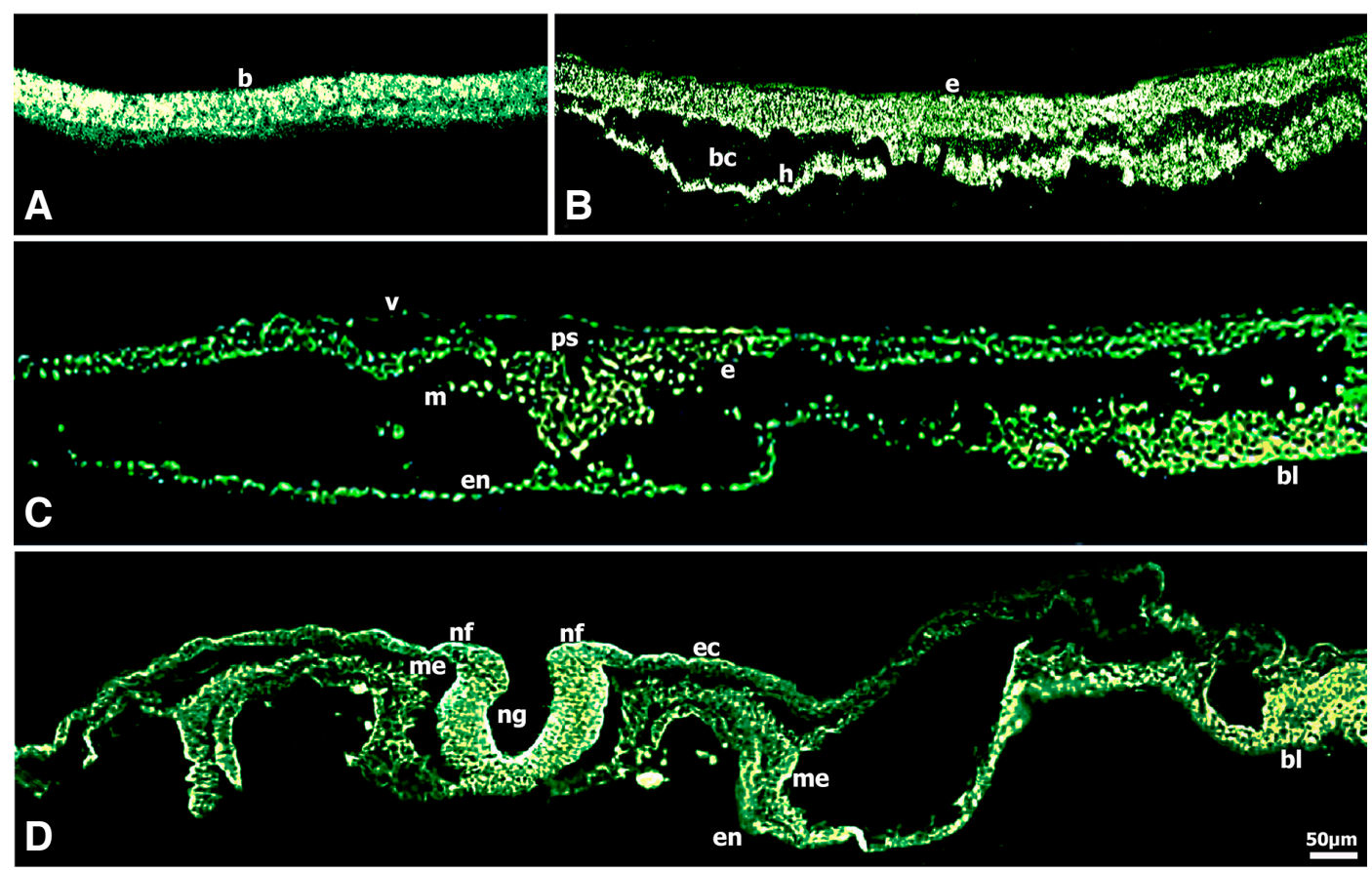

Fig. 2. Immunolocalization of CD44 in early chick embryos shown on transverse sections. (A) Embryo (blastoderm) at stage $\mathrm{XI}$ (morula) showed very intense CD44 immunoreactivity. (B) CD44 immunoreactivity was very intense lining the ventral surface of the epiblast and also in the hypoblast of embryos at stage XIII (blastula). (C) Epiblast cells ingressing in the primitive groove, migrating mesenchymal cells and blood islands showed very intense CD44 immunoreactivity in embryos at stage HH3-4 (gastrula). (D) CD44 immunoreactivity was very intense in the folding neural plate localized predominately to the basal surface and the apical external margins of neural folds, was intense in the presumptive neural crest, notochord, splanchnic mesoderm and very intense in blood islands in embryos at stage HH8 (4-somites). Bar $50 \mu \mathrm{m}$. observed if RNA was omitted from the reaction. We detected the predicted 226 bp PCR product in CD 44 CDNA derived from embryos at all stages of development studied. CD44 exhibited high transcript levels in stage XII embryos, showed a progressive slight decrease or steady maintenance up to stage $\mathrm{HH}$, then showed an increase in late stage $\mathrm{HH} 13$ embryos returning to levels of pre-gastrula stages (Fig. 1). In late stage $\mathrm{HH} 13$ embryos, the embryonic axis was micro-dissected and separated from the extraembryonic area, which included the vascular area (area vasculosa); CD44 gene expression was particularly prominent in the embryonic axis and in the extraembryonic vascular area in particular.

\section{Spatio-temporal patterns of CD44}

\section{CD44 expression pattern in very early embryos}

Immunofluorescence analysis showed the spatial and temporal distribution of CD44 from stage XI (morula) up to stage HH17 (29 somites) in the chick embryo (Figs. 2, 3, 4). Immunofluorescence staining was performed using the 1D10 chick monoclonal antibody that recognizes constant epitopes shared by standard CD44 and CD44 variants.

CD44 fluorescence was very intense in the blastoderm at stage XI (morula) (Fig. 2A). At stage XIII (blastula), CD44 fluorescence was very intense in the epiblast, particularly the cells on the ventral surface adjacent to the blastocoele and in the hypoblast (Fig. 2B). During gastrulation at stage $\mathrm{HH} 3-4$ (intermediate streak to definitive streak/ mid gastrula) (Fig. 2C), CD44 expression was very intense in the epiblast cells ingressing in the primitive groove, the migrating mesenchymal cells and the cells of the deep layer.

Worthy of note was the very intense fluorescence in the blood islands, masses of splanchnic mesodermal cells forming the extra-embryonic vascular area (area vasculosa) in the yolk sac.

At stage $\mathrm{HH} 8$ (4-somites), the neural folds are elevated and convergence is under way (Fig. 2D), interestingly, the folding neural plate showed polarity regulation of CD44 expression; in particular, very intense fluorescence was localized predominately to the cells of the floor plate luminal surface and to the cells in the apical external surface of the lateral curved neural folds. CD44 expression was intense in the presumptive neural crest region and notochord, was observed in lateral plate mesoderm and splanchnic endoderm and was very intense in the developing vascular area (vascular plexus).

\section{CD44 expression pattern in 13-to-22 somite embryos}

At the 13 somite stage $(\mathrm{HH} 11), \mathrm{CD} 44$ was widely expressed with very intense localization to the neural tube and the migrating neural crest cells, the notochord, the foregut lateral and ventral wall, and the developing myocardium and dorsal mesocardium (Fig. $3 \mathrm{~A}$ ). Of note was the very intense fluorescence in the developing vascular area (not shown).

At the 22 somite stage (HH14) (Fig. 3B), CD44 fluorescence was very intense in the neuroepithelial cells spanning the width of the mesencephalon and was distinct in the extracellular matrix in the mesencephalon lumen. Interestingly, the diencephalon showed polarity regulation of the CD44 expression, in that very intense fluorescence was localized predominately to the neuroepithelial cells adjacent to the encephalic lumen and to the diencephalon wall external surface, and to the optic stalks. Worthy of note was the very intense CD44 expression in the neural crest cells migrating to the optic stalks that will eventually populate the corneal stroma and participate in the development of the cornea. CD44 fluorescence was very intense in the notochord, pharynx, Rathke's pouch and infundibulum, dorsal and ventral aortae, the amnion and chorion. The migrating neural crest cells underlying the ectoderm and inserted into the pharynx and the periaortic regions showed very intense CD44 expression (Fig. 3B).

\section{CD44 expression pattern in 29-somite embryos}

By the 29-somite stage (HH17) (Fig. 4 A-C), CD44 expression was very intense in the mesencephalon, myelencephalon and metencephalon, otic vesicles, ganglia VII\&VIII and in the migratory 
neural crest cells underlying the ectoderm and inserted in the otic vesicles and colonizing the gut wall and the periaortic regions. Of note, the distinct CD44 fluorescence in the extracellular matrix in the mesencephalon, myelencephalon and otic vesicle lumens. $A$ section at the heart level (Fig. 4B) revealed very intense CD44 expression in the neural tube, dorsal root ganglia, notochord, dorsal aorta, gut, hepatic primordia (liver), myocardium and the singlelayered endocardium, the dermamyotome and in the dissociated mesenchymal cells of the sclerotome in somites (Fig. 4B).

Interestingly, in the trunk region at the somite level of the same embryo (Fig. 4C), the neural tube showed polarity regulation of the CD44 expression in that very intense fluorescence was localized predominately to the neuroepithelial cells adjacent to the neural tube lumen and to the external surface of the neural tube wall. CD44 fluorescence was very intense in the pre-and migratory neural crest cells, notochord, dermamyotome and dissociated mesenchymal cells of the sclerotome that are populated with neural crest cells in transit to the mesonephros, very intense in mesonephros and the adjacent lateral mesoderm that will form the mesonephric tubules, and was also intense in the more lateral somatic and splanchnic mesoderm, and very intense in the vascular area (not shown) (Fig. 4C).

\section{Perturbation of CD44 function}

Embryos at the intermediate to definitive streak stage (HH3-4) were treated with the chick monoclonal anti-CD44 antibody for $2 \mathrm{~h}$ and then cultured further on plain egg albumen for about 41 h. They showed distinct developmental abnormalities along the craniocaudal axis (Fig. $5 \mathrm{D}-\mathrm{F}$ ) compared with matched control embryos (Fig. 5 A-C).
In studying serial transverse sections of experimental embryos (Fig. 5 D-F), of particular interest were a strikingly unorganized extracellular matrix that formed "pools" in the heart and among the clumped mesodermal cell clusters, and the deteriorated basement membrane architecture that resulted in the collapse of tissue spaces and, consequently, the collapse of tissue/organ cytoarchitecture. The developing cranial and caudal neural tube cytoarchitecture was severely distorted, as shown by the neuroepithelium, which did not evidence the typical thickened, pseudostratified morphology of a coherent layer; instead, the neuroepithelial cells acquired a rounded morphology, were clumped and had collapsed. The emigration of neural crest cells from the neural tube was perturbed, in the sense that neural crest cells did not migrate but formed abnormal aggregates clustered to the ectoderm apical surface. Notochord formation was grossly abnormal, as shown by its oversized and flattened shape. The mesenchyme was clumped in appearance and there was abnormal intermingling with neuroepithelial and notochordal cells. Fig. 5B shows how the heart was malformed, the dorsal mesocardial cells were intermingling with the endocardium, and the cardiac jelly was grossly abnormal. Of note, formation of the dorsal aorta was impeded and the gut wall was thickened and disorganized. In transverse sections through the somite level, paraxial mesoderm cells flanking a grossly abnormal notochord showed retracted rounded up morphology, and appeared grouped in clusters in unorganized extracellular matrix "pools" instead of showing the characteristic paraxial mesoderm and epithelial somite morphology (Fig. 5F). The control embryos showed the characteristic neural tube, notochord, heart, gut, paraxial mesoderm and somite morphology in transverse sections through the cephalic, heart and somite regions (Fig. $5 \mathrm{~A}-\mathrm{C}$, respectively).
Fig. 3. Immunolocalization of CD44 in 13-to-22 somite chick embryos. (A) CD44 expression was very intense in the neural tube which showed polarity regulation, in notochord, foregut lateral and ventral wall, myocardium, dorsal mesocardium, pre-and migratory neural crest cells migrating along the somato-splanchnopleural mesoderm and endoderm routes to colonize the heart and the gut wall in embryos at stage $\mathrm{HH} 11$ (13 somites). (B) CD44 immunoreactivity was very intense in mesencephalon and diencephalon; the diencephalon showed polarity regulation of CD44 expression. Immunoreactivity was also very intense in optic stalks, infundibulum, notochord, pharynx and Rathke's pouch, dorsal and ventral aortae and in the migrating neural crest cells underlying the ectoderm and inserted into the developing optic vesicles, pharynx and the periaortic regions in embryos at stage $\mathrm{HH} 14$ (22 somites). Bar $50 \mu \mathrm{m}$.
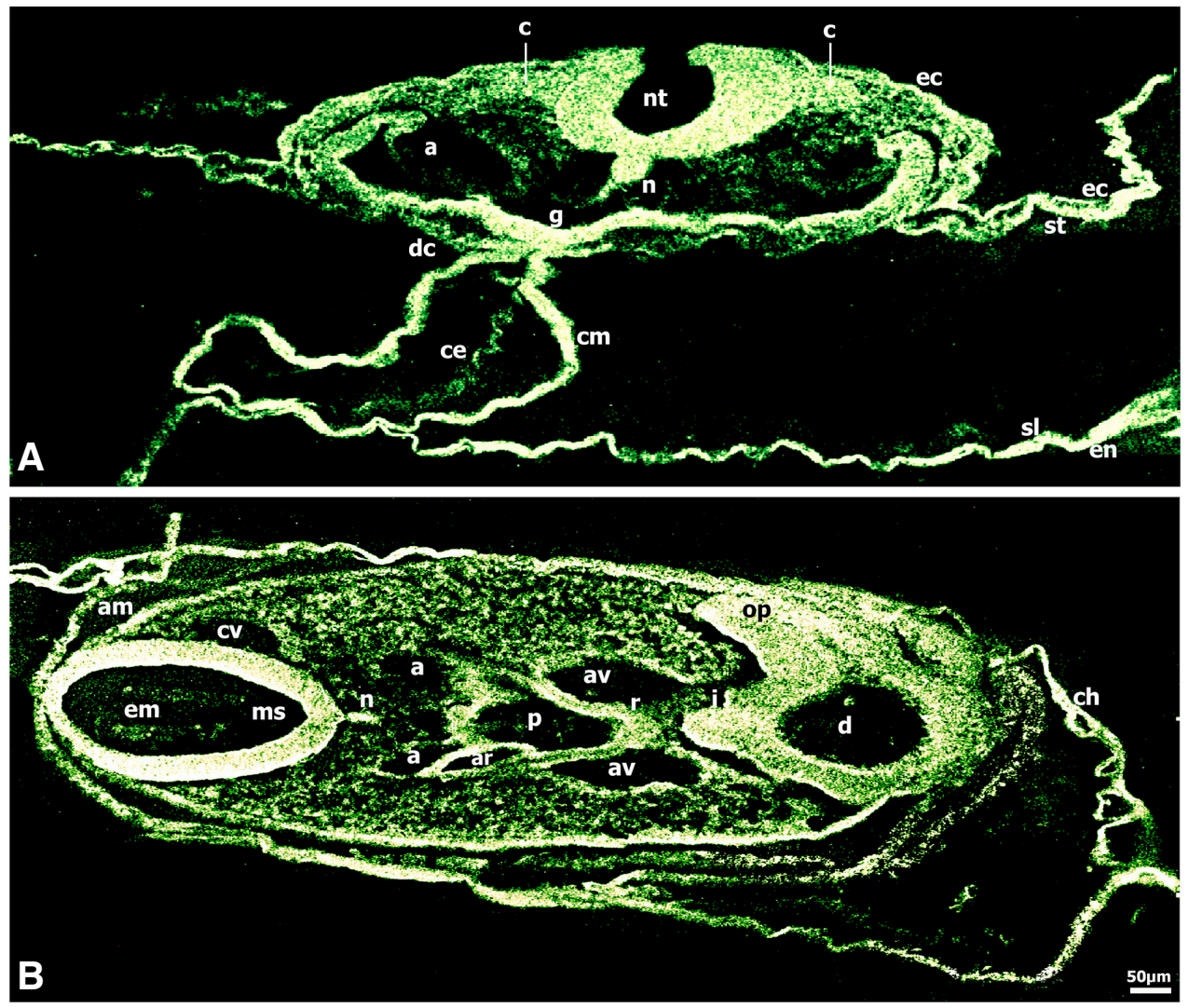


\section{Discussion}

In the present study, we presented new data on the time of the earliest expression of CD44 and novel CD44 distribution patterns in developing tissues and organs, and provided evidence of a distinctive functional role of CD44 during early embryogenesis. Of particular novel interest were the high levels of CD44 detected as early as the blastoderm XI and XII stages (morula, Figs. 1, 2A). Since zygotic expression starts in the midblastula stage (also called the midblastula transition) of chick embryo (Zagris et al., 1998), our results suggested that CD44 have already started as maternal transcripts in the morula embryo. Subsequently, CD44 expression exhibited slow decrease or steady maintenance in later stages during the hand-off-in genetic regulation from maternal to zygotic control; CD44 expression showed an increase in late stage $\mathrm{HH} 13$ ( $\mathrm{HH} 13+, 20$-to-21 somites) embryos similar to the levels of pre-gastrula stages (Fig. 1). The CD44 expression in the morula embryo may be essential for the rapid synthesis and/ or attachment of its ligand hyaluronan when cell-free spaces (embryonic cavities) have to be formed rapidly to facilitate the subsequent morphogenetic movements of gastrulation. Strikingly, hyaluronan has been shown to be synthesized at the blastula stage (XIII) of chick embryo (Skandalis et al., 2003); subsequently, hyaluronan is the major glycosaminoglycan synthesized during the primitive streak stages (gastrulation) of chick embryos
(Manasec 1975; Solursh 1976; Skandalis et al., 2003) and rat (Solursh and Morriss, 1977). The extensive hyaluronan synthesis at the blastula and gastrula stages is compatible with its role, in that hyaluronan, due to its structure and hydrophilic nature, forms hydrated gels promoting formation of extensive cell-free spaces and cell migration (Laurent and Fraser, 1992). The chick embryo, a compact blastoderm at stage XI (morula), is filled with an extensive cavity, the blastocoele, during the blastula stage (XIII). The rapid blastocoele formation facilitates extensive cell migration during early pattern formation at the gastrula stage ( $\mathrm{HH} 4$, definitive streak).

CD44 immunoreactivity was very intense in the blastoderm at stage XI (morula, Fig. 2A) and was detected in the epiblast and hypoblast, being most intense in the cells around the blas tocoele at stage XIII (blastula, Fig. 2B). During elongation of the primitive streak ( $\mathrm{HH} 3-4$, gastrulation), CD44 was very intense in the primitive streak where epiblast cells de-epithelialize ingress into the primitive groove and migrate laterally, in the migrating mesenchymal cells and the forming blood islands (Fig. 2C). The cells migrating into the blastocoele are known to synthesize and become coated with hyaluronan (Solursh and Morriss, 1977); the CD44-bound hyaluronan decorated with aggregating proteoglycans (i.e., aggrecan, versican) assemble the components into a pericellular matrix, and this pericellular coat keeps the cells dispersed while they migrate (reviewed by Toole, 1991, 2004).
Fig. 4. Immunolocalization of CD44 in chick embryo at stage $\mathrm{HH} 17$ (29 somites). (A) CD44 was very intense in mesencephalon, myelencephalon and metencephalon, in notochord, otic vesicles, ganglia, and in the migrating neural crest cells; the extracellular matrix showed distinct immunoreactivity in mesencephalon myelencephalon and otic vesicle lumens (B) At the heart level of the same embryo, CD44 immunoreactivity was very intense in neural tube, notochord, dermomyotome and dissociated mesenchymal cells of the sclerotome populated with migrating neural crest cells, myocardium and singlelayered endocardium, ductus venosus, dorsal aorta, gut, liver, and in migratory neural crest cells forming the dorsal root ganglia and colonizing the gut wall and the periaortic regions. (C) At the somite level, CD44 immunoreactivity was very intense in the neural tube which showed polarity regulation of the CD44 expression very intense in pre- and migratory neural crest cells, in notochord, dermamyotome and dissociated mesenchymal cells of the sclerotome populated with migrating neural crest cells in transit, very intense in mesonephros and the adjacent lateral mesoderm that will form the mesonephric tubules, and in the vascular area (not shown). Bar $50 \mu \mathrm{m}$
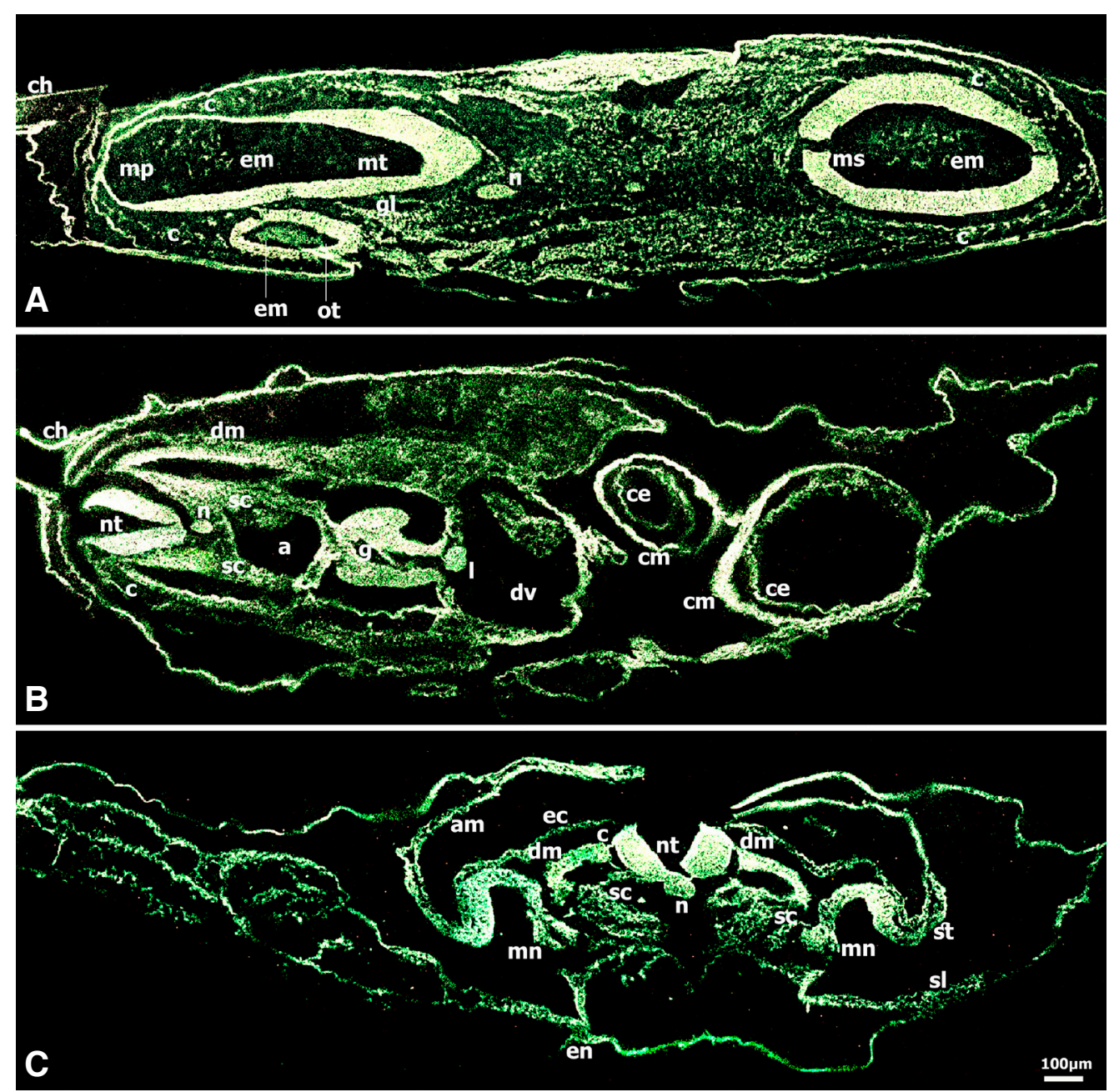
Significantly, our results showed that the folding neural plate exhibited polarity regulation of CD44 expression during formation of the neural tube (Fig. 2D); in particular, very intense CD44 expression was localized predominantly to the cells of the floor plate luminal surface and to the cells in the apical external surface of the lateral curved neural folds. Early work (Manasec, 1975) had detected large amounts of hyaluronan, especially along the lateral sides and groove of the folding neural plate.

It has been suggested that hyaluronan accumulation and its increased hydration contribute to the tissue elevation and folding that occur during formation of the neural tube from the neural plate (reviewed by Toole, 1991). The polarity regulation of CD44 expression can be correlated with the hyaluronan distribution, and this may attest to the synergism of these molecules in sculpturing the neural tube architecture. Later in development, of note was the polarity regulation of CD44 expression in the developing cranial and caudal neural tube (Figs. 3 A,B, 4C). CD44 expression was also very intense in the splanchnic mesoderm and the developing vascular area.

In our present study, of particular interest was the very intense CD44 expression in the pre-and migratory cranial and trunk neural crest cells, migrating along their defined dorsolateral and ventral pathways underlying the ectoderm and inserted into various developing organs (Figs. 3,4). CD44 expression was very intense in the ganglia formed from neural crest cells; in the optic stalks, otic vesicles, myocardium and endocardium, in the periaortic regions, mesonephros and the adjacent lateral mesoderm that will form the mesonephric tubules, gut lower and lateral wall, and pharynx tissues, populated predominantly by neural crest cells; and in somites, hepatic primordium (liver), amnion and chorion (Figs. 2, 3 , 4). Curiously, CD44 immunoreactivity was detected in the extracellular matrix of diencephalon, mesencephalon, metencephalon and myelencephalon and of otic/auditory vesicle lumens (Figs. 3B, $4 \mathrm{~A})$. There is some evidence that CD44 is not entirely membraneassociated but is also an integral constituent of the extracellular compartment (Cichy and Pure, 2003); it is possible that the released ectodomain of CD44, in association with hyaluronan and other extracellular matrix macromolecules, creates a scaffold for enzymes and growth factors. Previous studies showed CD44 expression in the heart, hepatic primordia, pharyngeal pouch, branchial arches and cleft, somites, limb-buds, odontogenic placodes, amnion and chorion of mice (Wheatley et al., 1993) and in cells of all three germ layers of rat embryos (Weber et al., 1996).

Previous work had reported expression of CD44 in cranial but not in trunk neural crest cells, in mesoderm of the regressed primitive streak (end bud/tail bud) and in some hemopoietic cells present in the blood stream of chick embryos at stages 3 to 20 ss, i.e. HH8 to HH13+ (3 to 20 somites), as revealed in immunostaining using an anti-CD44 A6v antibody (Corbel et al., 2000). In our work reported here, at the same stages (Figs. 2D, 3 A,B), we detected significant levels of CD44 widely expressed in the cranial as well as in the trunk neural crest cells, the neuroepithelium of the folding neural plate and the developing neural tube, in heart, pharynx and gut, the extra-embryonic vascular area and in the periaortic axial regions. These differences in the pattern of CD44 expression point to the differences in the specificity of the CD44 antibodies utilized in our studies. The CD44 clone A6v antibody used by the previous study (Corbel et al., 2000) presumably detected an epitope encoded by the CD44-6v variable exon on the cells expressing this CD44 variant; however, subsequent studies (Raushe and Knudson, 2002) pointed out that the lack of available chicken anti-CD44 antibodies had prevented detection of the CD44 protein and argued that the antibody (Av6) shown to stain chick cells (Corbel et al., 2000) was not well characterized. In our present work, we used a CD44s antibody (Halfter et al., 2005) that targets constant epitopes shared by standard CD44 and variants. Cells expressing the CD44-6v are known to share properties with metastasizing tumor cells (Wirth et al., 1993); in newborn rats, the expression pattern of CD44-6v-containing isoforms is restricted to proliferating mobile cells (Wirth et al., 1993; Weber et al., 1996). It is curious that the cranial but not the trunk migrating neural crest cells expressed the CD44-6v variable exon in the chick embryo (Corbel et al., 2000). This suggests differential regulation of the splicing by cell-specific transacting factors in cranial neural crest cells, and poses the intriguing question as to what behavior this variant isoform confers to this cell population.

The CD44 expression pattern we detected in our present work shows an overlap with the distribution of its ligand hyaluronan. Early work showed hyaluronan presence in the corneal stroma during the invasion of neural crest cells (Toole and Trelstad, 1971), the matrix of dissociated mesenchymal cells of the sclerotome (Kvist and Finnegan, 1970), the developing heart (Manasek et al., 1973), limb (Toole, 1972), in cell-free spaces underlying the ectoderm along neural crest cell defined pathways (Pratt et al., 1975) in chick, and in amniotic and yolk cavities and various organs in mouse embryos (Brown and Papaioannou 1993; Fenderson et al., 1993).

We have shown here that CD44 was expressed intensely in blood islands as they start forming at the gastrula stage (Fig. $2 \mathrm{C}$ ), and CD44 expression continued to be very intense in the developing extraembryonic vascular area at stage $\mathrm{HH} 8$ (neurula) (Fig. 2D) and at late stage $\mathrm{HH} 13$ (HH13+, 20-to-21 somites) (Fig. 1 ). Blood islands are masses of splanchnic mesodermal cells in the yolk sac, the first vascular forming tissue of the embryo, and differentiate into blood cells and blood vessels. Vasculogenesis and angiogenesis involve blood island cell proliferation, endothelial cell migration away from the cluster, aggregation, remodeling of the surrounding extracellular matrix, formation of collateral vessels that will form lumens over time, and ultimately a dense, complex vitelline plexus (blood vessel networks). The very intense CD44 expression in the blood islands implicate CD44 in the processes of vasculogenesis and angiogenesis through its ability to interact with hyaluronan and with growth factor VEGF (vascular endothelial growth factor) and its receptors (Nico 2001; Toole 2004; Arapatzi et al., 2022). The CD44 extra cellular part is known to interact with VEGFR-2 (VEGFreceptor-2); this activates association of the CD44 carboxy-terminus with ezrin, leads to actin cytoskeleton reorganization, and induces membrane ruffling, proliferation and migration of vascular endothelial cells, resulting in growth of new blood vessels (angiogenesis) (Millauer et al., 1993; Legg et al., 2002; Ponta et al., 2003; Tremmel et al., 2009). Hyaluronan breakdown products have been shown to have potent signaling capacity mediated through CD44 in regulating growth and vascular development of both the major blood vessels and the capillary plexus (West et al., 1985; Deed et al., 1997; Nandi et al., 2000; reviewed in Toole 2004; Tavianatou et al., 2019).

To investigate the developmental significance of the CD44 expression pattern in the early embryo, we used blocking antibodies directed against CD44 to perturb CD44-depended signalling pro- 

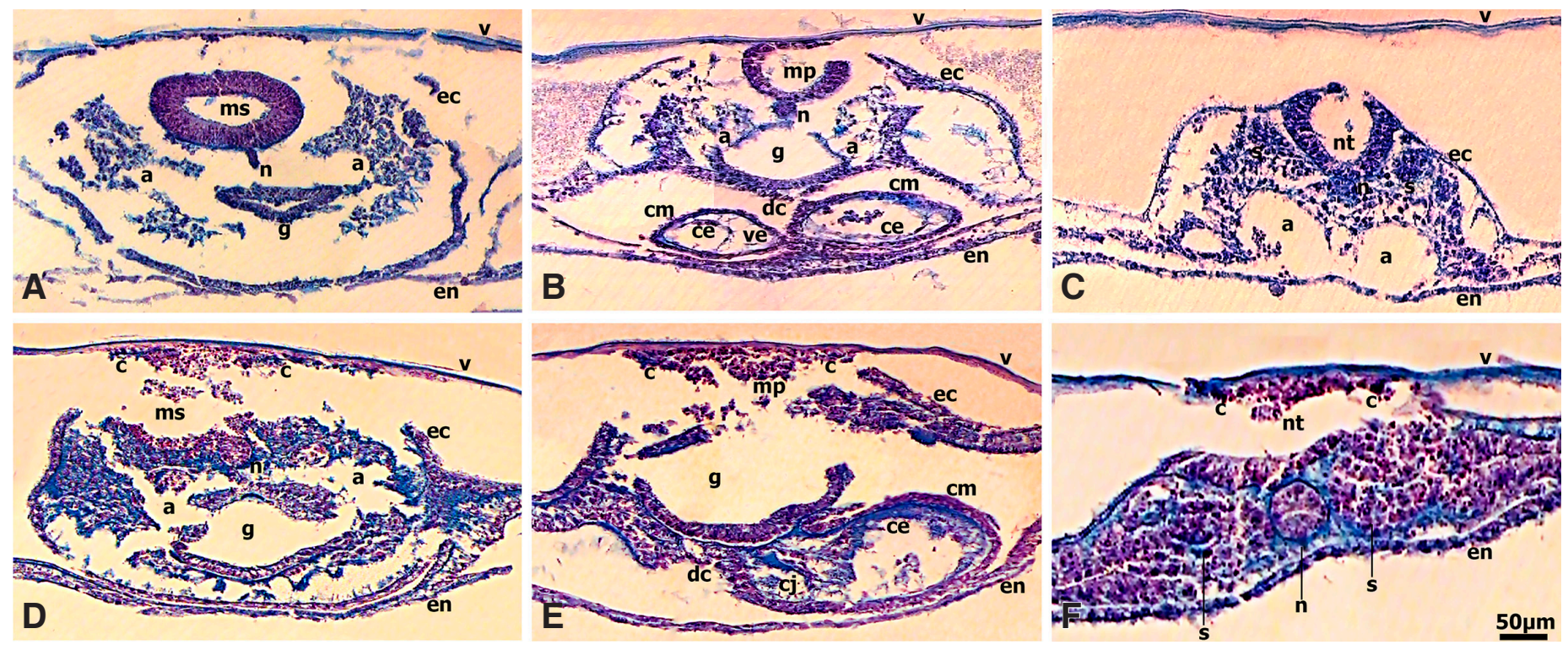

Fig. 5. Monoclonal anti-CD44 antibody perturbed specific morphogenetic processes in chick embryo. Embryos at stage HH3-4 (intermediate streak) were treated either with monoclonal IgG directed at chick CD44 (experimental) or plain Ringer solution (control) for $2 \mathrm{~h}$ then cultured on plain egg albumen for 41h. Transverse sections through brain (D), heart (E) and somite (F) levels of experimental embryo showed unorganized extracellular matrix, basement membrane and neural tube cytoarchitecture collapse, loss of tissue spaces, abnormal neural crest cell aggregates clustered to the ectoderm apical surface, oversized flattened notochord, clumped neuroectodermal and notochordal cells intermingling with clumped mesenchyme, abnormal thickening of heart and gut mesoderm, clustered paraxial mesoderm cells and absence of epithelial somites, and absence of blood vessels (D-F). Transverse sections through brain (A), heart (B) and somite (C) levels of control embryo showed normal tissue organization. Sections (7mm) stained with Alcian blue and nuclear fast red. Bar $50 \mu \mathrm{m}$.

grams. It was striking to see the loss of tissue spaces and an unorganized, grossly abnormal extracellular matrix that formed "pools" in the heart and among mesenchyme cell clusters in embryos treated by anti-CD44 blocking antibodies (Fig. 5 D-F). Specific processes that were impaired included the distorted encephalic and caudal neural tube cytoarchitecture due to the neuroepithelium collapse. Notochord formation was improper and not easily identifiable, as seen from its oversized flattened and often indistinct shape. There occurred abnormal intermingling of the clumped mesenchyme with clumped neuroectodermal and notochordal cells. Interestingly, neural crest cells failed to emigrate from the substratum on the dorsal neural tube and formed abnormal aggregates clustered to the ectoderm apical surface; this indicates that CD44 signaling is pivotal for the emigration of crest cells from the neural tube. Noteworthy too was the complete absence of blood vessels and the abnormal thickening of heart and gut mesoderm. The somite region showed loss of tissue spaces; mesoderm cells flanking an abnormal notochord showed retracted rounded up morphology and appeared grouped in clusters surrounded by extracellular matrix "pools" instead of showing the characteristic paraxial mesoderm and epithelial somite (Fig. 5F). The control embryos exhibited proper tissue modelling and organization (Fig. 5 A-C).

In an early work (Fisher and Solursh, 1977), chick embryos at stage HH5-to-HH6 (head process-to-head fold) injected in ovo with Streptomyces hyaluronidase (specifically degrades hyaluronan) showed a marked loss of intercellular space and a decrease in extracellular matrix. The notochord was flattened and somewhat disorganized in appearance, and the head mesenchyme appeared clumped and resting on the endoderm and only rarely retained connection with neural or non-neural ectoderm. Other studies showed that treatment with the hyaluronan-specific Streptomyces hyaluronidase did not inhibit migration of neural crest cells in chick (Anderson and Meier, 1982) and rat (Morriss-Kay et al., 1986) embryos.

In our present study, detailing CD44 expression pattern in the very early chick embryo, of particular interest were the high levels of CD44 detected in the morula embryo (stage XI blastoderm), suggestive of a maternally stored transcript. Intriguingly, CD44 presence was nearly coincident and seemed to be essential for the rapid synthesis and deposition of hyaluronan. CD44 expression was very intense in the developing central nervous system, in cranial and caudal pre-and migratory neural crest cells, in tissues populated predominantly by neural crest cells, and in several other areas of active cell migration such as the blood islands and the presumptive mesonephric tubules. Of particular interest was the polarity regulation of CD44 expression to the cells of the floor plate and the curved neural folds during neural plate folding, and to the developing central nervous system. Our observations support a developmentally regulated expression pattern of CD44 gene activity in the very early embryo. Inhibition of CD44 function by blocking antibodies showed that CD44 monitors changes consistent with its known biochemical features and interactions with hyaluronan, growth factors, receptors and other signaling molecules. CD44 as a signaling molecule is not only crucial for maintaining extracellular matrix, basement membrane architecture and tissue space integrity, but also seems to participate in signaling programs that guide neural crest cell emigration, proliferation, paraxial mesoderm segmentation and tissue patterning. 


\section{Materials and Methods}

\section{Animal studies and ethics statement}

Fertilized chicken eggs (supplied by the Epirus Poultry Co., Ioannina, Greece) were incubated at $37.5^{\circ} \mathrm{C}$ under high humidity. The chick embryo studies and all procedures were performed in accordance with the guidelines of the National Ethical Commission for Animal Research (Ministry of Education, Greece) and the Institutional Animal Care and Use Committee(University of Patras).

\section{Reverse transcription-PCR (RT-PCR)}

The presence of CD44 mRNA at various stages of the early chick embryo was assessed by PCR amplification from mRNA derived cDNA. Total RNA was prepared (RNeasy Mini Kit protocol, Qiagen) from chick embryos at stages XII (early blastula), $\mathrm{HH} 2$ (initial streak/early gastrula), HH4 (definitive streak/late gastrula), HH5 (head process) and late stage $\mathrm{HH} 13$ (HH13+, 20-21 somites); in the embryos at late stage $\mathrm{HH} 13$, the embryonic axis was microdissected and separated from the extraembryonic area, which included the area vasculosa. Attention was paid to the exact developmental stage of the embryos according to Eyal-Giladi and Kochav (1976, X symbol) and Hamburger and Hamilton (1951, HH symbol). PCR primers were 5'- GAG TGT AGC GGT ACG AAG - 3' (sense, position 1258) and 5'- TAG GAA CTG GGA ACT GAC - 3' (antisense, position 1483) specific for a fragment of 226-bp (from 1258 to 1483) of chick CD44 mRNA. For chick $\beta$-actin, a fragment of 187-bp was amplified with the following primers (Corpuz et al., 2000; Zagris et al., 2011): sense 5'- CGG TAT TGT CAC CAA CTG G - 3' and antisense 5'- TGG CTA CAT ACA TGG CTG G - 3' were used in a parallel reaction as the CD44 primers. The CD44 primers were designed (Primer Premier software/ PREMIER Biosoft International) as oligonucleotides complimentary to regions of the known sequences encoding for chick "CD44-like" (http://www. ncbi.nlm.nih.gov.; AF153205) and purchased from Invitrogen/ Thermo Fisher Scientific (Waltham, Mass, USA). Single stranded cDNA was synthesized employing as template $2 \mu \mathrm{g}$ of total RNA from embryos according to the manufacturer OneStep RT-PCR Kit protocol (Qiagen); the RNA was omitted from the reaction in the negative control samples. Following reverse transcription $\left(50^{\circ} \mathrm{C}\right.$ for $30 \mathrm{~min})$, amplification conditions were started at $95^{\circ} \mathrm{C}$ for $15 \mathrm{~min}$, and then subjected to 35 cycles of [denaturation $94^{\circ} \mathrm{C}$ for $30 \mathrm{sec}$, annealing $51^{\circ} \mathrm{C}\left(55^{\circ} \mathrm{C}\right.$ for $\beta$-actin) for $1 \mathrm{~min}$, elongation $72^{\circ} \mathrm{C}$ for 1 min], and one cycle of extension $72^{\circ} \mathrm{C}$ for $10 \mathrm{~min}$. PCR amplification products $(2 \mu \mathrm{l} /$ lane $)$ were separated on a $5 \%$ polyacrylamide gel and stained with ethidium bromide. A 100-10000bp ladder was used as a marker (GeneRuler DNA Ladder Mix, Fermentas). The bands were quantified by a laser scanning densitometry and computer integration (Scion Image PC). The values were normalized to the $\beta$-actin transcript level.

\section{Embryos and CD44 Immunolabeling}

Chick embryos at stages XI (morula), XIII (blastula), HH3-4 (intermediate to definitive streak/intermediate gastrula), $\mathrm{HH} 8$ (four somites), HH11 (13 somites), HH14 (22 somites) and HH17 (29 somites) were removed from their eggs and adhering yolk was cleaned off with fine dissecting needles. The embryos were fixed, dehydrated, embedded in paraffin and sectioned $(7 \mu \mathrm{m})$ serially as described previously (Soulintzi and Zagris 2007; Georgadaki and Zagris 2014).
Serial sections from embryos at the stages described above were used.

Immunolabeling was performed as described previously (Soulintzi and Zagris, 2007; Zagris et al., 2011). The chick monoclonal anti-CD44 antibody (clone 1D10, Halfter et al., 2005) was used at a final concentration of $5 \mu \mathrm{g} / \mathrm{ml}$ in PBS and the sections were incubated overnight at $37.5^{\circ} \mathrm{C}$ in a moist chamber. The fluoresceinconjugated goat anti-mouse IgG secondary antibody (Santa Cruz Biotech., USA) was used at a final concentration of $5 \mu \mathrm{g} / \mathrm{ml}$ in PBS for $1 \mathrm{~h}$ at $37.5^{\circ} \mathrm{C}$ in a moist chamber. The sections were rinsed three times (20 min each) in PBS and mounted in glycerol-Mowiol 4-88. Sections were observed and photographed with epifluorescent illumination, using filters selective for fluorescein. For control slides, primary antibody was omitted and sections were incubated with mouse IgG and with fluoresceinated secondary antibody. The chick monoclonal anti-CD44 antibody (clone 1D10) was obtained from the Developmental Studies Hybridoma Bank (University of lowa, lowa City, lowa, USA).

\section{Function-blocking CD44 antibodies}

Embryos at stage HH3-4 (intermediate to definitive streak) were removed from their eggs, cleaned of adhering yolk, placed in 400 $\mu$ l Ringer solution containing the chick monoclonal anti-CD44 antibody $1 \mathrm{D} 10(1 \mu \mathrm{g} / \mathrm{ml}$ final concentration) in a microwell (G20 Culture slide; Arthur Thomas, Philadelphia, Pa., USA) and incubated for 2 $\mathrm{h}$ at $37.5^{\circ} \mathrm{C}$. The antibody was used at $1 \mu \mathrm{g} / \mathrm{ml}$ final concentration, which was the concentration that produced consistent results. At the end of the incubation period, the embryos were washed in Ringer solution, flattened with their epiblast side against the surface of vitelline membrane support rafts, and cultured on plain egg albumen at $37.5^{\circ} \mathrm{C}$. Embryos incubated in plain Ringer solution or in Ringer solution containing mouse IgG, subsequently cultured on plain egg albumen in a parallel culture, served as controls. Embryos were photographed after $41 \mathrm{~h}$ in culture, fixed in Carnoy fixative, dehydrated, embedded in paraffin and sectioned (7 $\mu \mathrm{m})$ serially. Sections were deparaffinized and stained in Alcian blue 8GX (stains both sulphated and non-sulphated proteoglycans) and counterstained with Nuclear fast red (stains nuclei) (Alcian blue method, pH 2.5; Humason, 1972) to study how the CD44 absence had affected the extracellular matrix integrity and the tissue/organ organization in the very early embryo.

Thirty-five embryos (10 control, 25 experimental) were used in the course of this investigation. Seven embryos, usually five experimental and two controls, were cultured per experiment. Embryos, cultured media and glassware were handled under sterile conditions.

\section{Competing interests}

The authors declare that no competing interests exist.

Acknowledgments

This work was supported by grants from the European Social Fund (ESF), Operational Program for Educational and Vocational Training II (EPEAEK II) particularly the Program "PYTHAGORAS II" and from the University of Patras ("K. Karatheodori" grant B.397).

\section{References}

ALHO A. M., UNDERHILL C. B. (1989). The hyaluronate receptor is preferentially expressed on proliferating epithelial cells. Journal of Cell Biology 108: 1557-1565. https://doi.org/10.1083/jcb.108.4.1557 
ANDERSON C. B., MEIER S. (1982). Effect of hyaluronidase treatment on the distribution of cranial neural crest cells in the chick embryo. Journal of Experimental Zoology 221: 329-335. https://doi.org/10.1002/jez.1402210308

ARAPATZI C., ROUNI G., KOSTOUROU V. (2022). Vascular cell-matrix adhesion in development and cancer. The International Journal of Developmental Biology 66: 103-113. https://doi.org/10.1387/ijdb.210204vk

ARUFFO A., STAMENKOVIC I., MELNICK M., UNDERHILL C. B., SEED B. (1990). CD44 is the principal cell surface receptor for hyaluronate. Cell 61: 1303-1313. https://doi.org/10.1016/0092-8674(90)90694-A

BROWN J.J., PAPAIOANNOU V.E. (1993). Ontogeny of hyaluronan secretion during early mouse development. Development 117: 483-492. https://doi.org/10.1242/ dev.117.2.483

CICHY J., PURÉ E. (2003). The liberation of CD44. Journal of Cell Biology 161: 839843. https://doi.org/10.1083/jcb.200302098

CORBEL C., LEHMANN A., DAVISON F. (2000). Expression of CD44 during early development of the chick embryo. Mechanisms of Development 96: 111-114. https://doi.org/10.1016/S0925-4773(00)00347-6

CORPUZ L. M., DUNLEVY J. R., HASSELL J. R., CONRAD A. H., CONRAD G. W. (2000). Molecular cloning and relative tissue expression of decorin and lumican in embryonic quail cornea. Matrix Biology 19: 699-704. https://doi.org/10.1016/ S0945-053X(00)00117-7

CULTY M., NGUYEN H. A., UNDERHILL C. B. (1992). The hyaluronan receptor (CD44) participates in the uptake and degradation of hyaluronan. Journal of Cell Biology 116: 1055-1062. https://doi.org/10.1083/jcb.116.4.1055

DEED R., ROONEY P., KUMARP., NORTON J. D., SMITH J., FREEMONTA. J., KUMARS. (1997). Early-response gene signalling is induced by angiogenic oligosaccharides of hyaluronan in endothelial cells. Inhibition by non-angiogenic, high-molecular-weight hyaluronan. International Journal of Cancer 71:251-256. https://doi.org/10.1002/ (SICI)1097-0215(19970410)71:2<251::AID-IJC21>3.0.C0;2-J

EVANKO S., TAMMI M., TAMMI R., WIGHT T. (2007). Hyaluronan-dependent pericellular matrix. Advanced Drug Delivery Reviews 59: 1351-1365. https://doi. org/10.1016/j.addr.2007.08.008

EYAL-GILADI H., KOCHAV S. (1976). From cleavage to primitive streak formation: A complementary normal table and a new look at the first stages of the development of the chick. Developmental Biology 49: 321-337. https://doi.org/10.1016/00121606(76)90178-0

FENDERSON B. A., STAMENKOVIC I., ARUFFO A. (1993). Localization of hyaluronan in mouse embryos during implantation, gastrulation and organogenesis. Differentiation 54: 85-98. https://doi.org/10.1111/j.1432-0436.1993.tb01591.x

FISHER M., SOLURSH M. (1977). Glycosaminoglycan localization and role in maintenance of tissue spaces in the early chick embryo. Development 42: 195-207. https://doi.org/10.1242/dev.42.1.195

FLANAGAN B.F., DALCHAU R., ALLEN A. K., DAAR A. S., FABRE J. W. (1989). Chemical composition and tissue distribution of the human CDw44 glycoprotein. Immunology 67: 167-175

GEORGADAKI K., ZAGRIS N. (2014). Neurocan developmental expression and function during early avian embryogenesis. Research Journal of Developmental Biology 1: 3. https://doi.org/10.7243/2055-4796-1-3

GÜNTHERT U. (1993). CD44: A Multitude of Isoforms with Diverse Functions. In Adhesion in Leukocyte Homing and Differentiation (Ed. Dunon D., Mackay C. R. Imhof B. A.). Current Topics in Microbiology and Immunology, Vol. 184. Springer Berlin Heidelberg, Berlin, Heidelberg, pp. 47-63. https://doi.org/10.1007/978-3642-78253-4_4

HALFTER W., WILLEM M., MAYER U. (2005). Basement Membrane-Dependent Survival of Retinal Ganglion Cells. Investigative Opthalmology \& Visual Science 46: 1000-1009. https://doi.org/10.1167/iovs.04-1185

HAMBURGER V., HAMILTON H. L. (1951). A series of normal stages in the development of the chick embryo. Journal of Morphology 88: 49-92. https://doi. org/10.1002/jmor.1050880104

HUA Q., KNUDSON C.B., KNUDSON W. (1993). Internalization of hyaluronan by chondrocytes occurs via receptor-mediated endocytosis. Journal of Cell Science 106: 365-375. https://doi.org/10.1242/jcs.106.1.365

HUGHES E.N., AUGUST J.T. (1981). Characterization of plasma membrane proteins identified by monoclonal antibodies. Journal of Biological Chemistry 256: 664-671. https://doi.org/10.1016/S0021-9258(19)70025-8
HUMASON G. L. (1972). Animal Tissue Techniques. Freeman and Co., San Francisco. KNUDSON C. B., KNUDSON W. (1993). Hyaluronan-binding proteins in development tissue homeostasis, and disease. The FASEB Journal 7: 1233-1241. https://doi. org/10.1096/fasebj.7.13.7691670

KNUDSON W. (1998). The role of CD44 as a cell surface hyaluronan receptor during tumor invasion of connective tissue. Frontiers in Bioscience 3: d604-615. https:// doi.org/10.2741/A305

KNUDSON W., CHOW G., KNUDSON C. B. (2002). CD44-mediated uptake and degradation of hyaluronan. Matrix Biology 21: 15-23. https://doi.org/10.1016/ S0945-053X(01)00186-X

KVIST T. N., FINNEGAN C. V. (1970). The distribution of glycosaminoglycans in the axial region of the developing chick embryo. I. Histochemical analysis. Journal of Experimental Zoology 175: 221-239. https://doi.org/10.1002/jez.1401750209

LAURENT T. C., FRASER J. R. E. (1992). Hyaluronan. The FASEB Journal 6: 23972404. https://doi.org/10.1096/fasebj.6.7.1563592

LEGG J. W., LEWIS C. A., PARSONS M., NG T., ISACKE C. M. (2002). A novel PKCregulated mechanism controls $C D 44-$ ezrin association and directional cell motility Nature Cell Biology 4: 399-407. https://doi.org/10.1038/ncb797

LESLEY J., HYMAN R., KINCADE P. W. (1993). CD44 and Its Interaction with Extracellular Matrix. In Advances in Immunology Volume 54 (Ed. Dixon F. J.). Advances in Immunology, Vol. 54. Academic Press, pp. 271-335. https://doi.org/10.1016/ S0065-2776(08)60537-4

MANASEK F. J. (1975). The Extracellular Matrix: A Dynamic Component of the Developing Embryo. In Current Topics in Developmental Biology (Ed. Moscona A. A., Monroy A.). Vol. 10. Academic Press, pp. 35-102. https://doi.org/10.1016/ S0070-2153(08)60038-

MILLAUER B. (1993). High affinity VEGF binding and developmental expression suggest Flk-1 as a major regulator of vasculogenesis and angiogenesis. Cell 72 835-846. https://doi.org/10.1016/0092-8674(93)90573-9

MORRISS-KAY G. M., TUCKETT F., SOLURSH M. (1986). The effects of Streptomyces hyaluronidase on tissue organization and cell cycle time in rat embryos Development 98: 59-70. https://doi.org/10.1242/dev.98.1.59

NANDI A., ESTESS P., SIEGELMAN M. H. (2000). Hyaluronan anchoring and regulation on the surface of vascular endothelial cells is mediated through the functionally active form of CD44. Journal of Biological Chemistry 275: 14939-14948. https:// doi.org/10.1074/jbc.275.20.14939

NICO B., VACCA A., DE GIORGIS M., RONCALI L., RIBATTI D. (2001). Vascular endothelial growth factor and vascular endothelial growth factor receptor-2 expression in the chick embryo area vasculosa. The Histochemical Journal 33 283-286. https://doi.org/10.1023/A:1017977007479

PICKER L. J., NAKACHE M., BUTCHER E. C. (1989). Monoclonal antibodies to human lymphocyte homing receptors define a novel class of adhesion molecules on diverse cell types. Journal of Cell Biology 109: 927-937. https://doi.org/10.1083/ jcb.109.2.927

PONTA H., SHERMAN L., HERRLICH P. A. (2003). CD44: From adhesion molecules to signalling regulators. Nature Reviews Molecular Cell Biology 4: 33-45. https:// doi.org/10.1038/nrm1004

PRATT R.M., LARSEN M.A., JOHNSTON M.C. (1975). Migration of cranial neural crest cells in a cell-free hyaluronate-rich matrix. Developmental Biology 44: 298 305. https://doi.org/10.1016/0012-1606(75)90400-5

ROUSCHE K. T., KNUDSON C. B. (2002). Temporal expression of CD44 during embryonic chick limb development and modulation of its expression with retinoic acid. Matrix Biology 21: 53-62. https://doi.org/10.1016/S0945-053X(01)00189-5

SHERMAN L., SLEEMAN J., HERRLICH P., PONTA H. (1994). Hyaluronate receptors: key players in growth, differentiation, migration and tumor progression. Current Opinion in Cell Biology 6: 726-733. https://doi.org/10.1016/0955-0674(94)90100-7

SHERMAN L., WAINWRIGHT D., PONTA H., HERRLICH P. (1998). A splice variant of CD44 expressed in the apical ectodermal ridge presents fibroblast growth factors to limb mesenchyme and is required for limb outgrowth. Genes \& Development 12: 1058-1071. https://doi.org/10.1101/gad.12.7.1058

SKANDALIS S. S., GIALELI C., THEOCHARIS A. D., KARAMANOS N. K. (2014) Advances and Advantages of Nanomedicine in the Pharmacological Targeting of Hyaluronan-CD44 Interactions and Signaling in Cancer. In Hyaluronan Signaling and Turnover (Ed. Simpson M. A., Heldin P.). Advances in Cancer Research, Vol. 123. Academic Press, pp. 277-317. https://doi.org/10.1016/B978-0-12-8000922.00011-3 


\section{K. Konstantopoulos et al.}

SKANDALIS S. S., THEOCHARIS A. D., PAPAGEORGAKOPOULOU N., ZAGRIS N. (2003). Glycosaminoglycans in early chick embryo. The International Journal of Developmental Biology 47: 311-314.

SOLURSH M. (1976). Glycosaminoglycan synthesis in the chick gastrula. Developmental Biology 50: 525-530. https://doi.org/10.1016/0012-1606(76)90171-8

SOLURSH M., MORRISS G. M. (1977). Glycosaminoglycan synthesis in rat embryos during the formation of the primary mesenchyme and neural folds. Developmental Biology 57: 75-86. https://doi.org/10.1016/0012-1606(77)90355-4

SOULINTZI N., ZAGRIS N. (2007). Spatial and Temporal Expression of Perlecan in the Early Chick Embryo. Cells Tissues Organs 186: 243-256. https://doi. org/10.1159/000107948

SRETAVAN D.W., FENG L., PURÉ E., REICHARDT L.F. (1994). Embryonic neurons of the developing optic chiasm express L1 and CD44, cell surface molecules with opposing effects on retinal axon growth. Neuron 12: 957-975. https://doi. org/10.1016/0896-6273(94)90307-7

TAVIANATOU A. G., CAON I., FRANCHI M., PIPERIGKOU Z., GALESSO D., KARAMANOS N. K. (2019). Hyaluronan: molecular size-dependent signaling and biological functions in inflammation and cancer. The FEBS Journal 286: 2883-2908. https:// doi.org/10.1111/febs. 14777

THORNE R. F., LEGG J. W., ISACKE C. M. (2004). The role of the CD44 transmembrane and cytoplasmic domains in co-ordinating adhesive and signalling events. Journal of Cell Science 117: 373-380. https://doi.org/10.1242/jcs.00954

TOOLE B. P. (1972). Hyaluronate turnover during chondrogenesis in the developing chick limb and axial skeleton. Developmental Biology 29: 321-329. https://doi. org/10.1016/0012-1606(72)90071-1

TOOLE B. P. (1991). Proteoglycans and Hyaluronan in Morphogenesis and Differentiation. In Cell Biology of Extracellular Matrix. Springer, Boston, MA, pp. 305-341. https://doi.org/10.1007/978-1-4615-3770-0_10

TOOLE B. P. (2004). Hyaluronan: from extracellular glue to pericellular cue. Nature Reviews Cancer 4: 528-539. https://doi.org/10.1038/nrc1391

TOOLE B. P., TRELSTAD R. L. (1971). Hyaluronate production and removal during corneal development in the chick. Developmental Biology 26: 28-35. https://doi. org/10.1016/0012-1606(71)90104-7
TREMMEL M., MATZKE A., ALBRECHTI., LAIB A. M., OLAKUV., BALLMER-HOFER K. CHRISTOFORI G., HÉROULT M., AUGUSTIN H. G., PONTA H., ORIAN-ROUSSEAU V. (2009). A CD44v6 peptide reveals a role of CD44 in VEGFR-2 signaling and angiogenesis. Blood 114: 5236-5244. https://doi.org/10.1182/blood-2009-04-219204

TROWBRIDGE I. S., LESLEY J., SCHULTE R., HYMAN R., TROTTER J. (1982) Biochemical characterization and cellular distribution of a polymorphic, murine cell-surface glycoprotein expressed on lymphoid tissues. Immunogenetics 15: 299-312. https://doi.org/10.1007/BF00364338

UNDERHILL C. (1992). CD44: The hyaluronan receptor. Journal of Cell Science 103 293-298. https://doi.org/10.1242/jcs.103.2.293

WEBER B., RÖSEL M., ARCH R., MÖLLER P., ZÖLLERM. (1996). Transient expression of CD44 variant isoforms in the ontogeny of the rat: Ectoderm-, endoderm- and mesoderm-derived cells express different exon combinations. Differentiation 60 17-29. https://doi.org/10.1046/j.1432-0436.1996.6010017.x

WEST D. C., HAMPSON I. N., ARNOLD F., KUMAR S. (1985). Angiogenesis Induced by Degradation Products of Hyaluronic Acid. Science 228: 1324-1326. https://doi. org/10.1126/science. 2408340

WHEATLEY S.C., ISACKE C.M., CROSSLEY P.H. (1993). Restricted expression of the hyaluronan receptor, CD44, during postimplantation mouse embryogenesis suggests key roles in tissue formation and patterning. Development 119: 295-306 https://doi.org/10.1242/dev.119.2.295

WIRTH K., ARCH R., SOMASUNDARAM C., WEBER B., ZÖLLER M., HOFFMANN M., HERRLICH P., HERRLICH P. (1993). Expression of CD44 isoforms carrying metastasis-associated sequences in newborn and adult rats. European Journal of Cancer 29: 1172-1177. https://doi.org/10.1016/S0959-8049(05)80310-7

ZAGRIS N., GILIPATHI K., SOULINTZI N., KONSTANTOPOULOS K. (2011). Decorin developmental expression and function in the early avian embryo. The International Journal of Developmental Biology 55: 633-639. https://doi.org/10.1387/ ijdb.113321nz

ZAGRIS N., KALANTZIS K., GUIALIS A. (1998). Activation of embryonic genome in chick. Zygote 6: 227-231. https://doi.org/10.1017/S0967199498000161 